\title{
EFFECT OF ACCELERATED AGING ON COLOR STABILITY OF NANO HY- BRID CERAMICS CEMENTED WITH THREE TYPES OF RESIN CEMENTS
}

\author{
Mohamed A. Aref ${ }^{*}$, Hussein R. Mohammed ${ }^{* *}$, Tamer A. Hamza ${ }^{* * *}$
}

\begin{abstract}
Objective: The objective of the current study was to evaluate the effect of artificial aging on the color stability of IPS e.max and CERASMART cemented with 2 types of resin cements and a flowable composite. Materials and Methods: Thirty ceramic disks were machined to a uniform thickness of $0.5 \mathrm{~mm}$ and divided into two groups, 15 disks each, according to the type of ceramic material. Each group was then subdivided into three subgroups according to the type of cement used $(\mathrm{n}=5)$. Each material was polished according to the manufacturer's instructions using the same polishing technique and then resin cement was placed with controlled thickness of $0.1 \mathrm{~mm}$ by means of a Teflon mold using two resin cements (RelyX Ultimate and RelyX Veneer) and a composite resin (Filtek Z350 flowable composite). A laboratory spectrophotometer was used to measure the color differences $(\Delta E)$ of each specimen immediately after 24 hours of curing and after artificial aging in a weathering device for 300 hours. Results: According to Two-Way ANOVA test, both ceramic materials and resin cements are significantly affected by artificial aging. Disks cemented with RelyX Ultimate showed lowest $\Delta \mathrm{E}$ values (4.75) followed by disks cemented with RelyX Veneer (5.03) and the disks cemented with Filtek Z350 flowable composite represent the highest $\Delta \mathrm{E}$ values (5.29). Moreover, disks made from CERASMART material showed more color change than disks made from IPS e.max (5.33 and 4.72 respectively). Conclusion: The color changes of resin cement materials in all groups were above the clinically acceptable value $(\Delta \mathrm{E} \geq 3.3)$. Rely $\mathrm{X}$ Ultimate showed higher color stability than the other tested materials. Resin cements affect the final color of thin restorations. IPS e.max CAD showed better color stability than CERASMART CAD.
\end{abstract}

KEY WORDS: Accelerated aging, Color stability, Nano-hybrid ceramics

\section{INTRODUCTION}

Ceramic restorations have the advantages of excellent optical properties and the ability to mimic the tooth structure compared with metal-ceramic systems ${ }^{(1)}$. However, there are many factors that affect the esthetics of ceramic restorations including color of the tooth/substructure ${ }^{(2)}$, the ceramic material used and its thickness ${ }^{(3,4)}$, also, thickness, shade and polymerization method of the resin cement $^{(5,6)}$.

IPS e.max is one of the most commonly used ceramic materials which is a lithium disilicate glass ceramics that has optimized translucency, durability, and strength. It had a significant improvement in clinical performance in terms of optical behavior and flexural strength ${ }^{(7)}$. Recently, CERASMART, which is a nano hybrid ceramic material, has been introduced. It combines the characteristics of a ceramic and a composite ${ }^{(8)}$. It is possible that the chemical composition of the material and its resin content may affect its color stability after accelerated ageing ${ }^{(9)}$.

Resin cements are the material of choice for the cementation of tooth-colored restorations ${ }^{(10)}$. Light-cured resin cements are usually used for

\footnotetext{
* Dentist at the Ministry of Health - Egypt.

** Lecturer, Crown and Bridge Department Faculty of Dental Medicine - Al-Azhar University. Cairo, Egypt. *** Professor, Crown and Bridge Department Faculty of Dental Medicine - Al-Azhar University. Cairo, Egypt.
} 
cementation of laminate veneers because of their great color stability ${ }^{(11)}$. Dual-cured resin cements have been developed to combine some of the favorable characteristics of chemical and light cured cements ${ }^{(12)}$. These materials have superior mechanical properties ${ }^{(13)}$. Moreover, the chemicalcure component is responsible of completing polymerization process in deeper areas where light is attenuated ${ }^{(12)}$. However, dual-cured resin cements contain aromatic tertiary amine in their composition, which might cause color changes in the cement over time ${ }^{(13)}$. Recently, dual-cured resin cements have been introduced which are free from the aromatic tertiary amine.

Some authors have suggested cementing laminate veneers with flowable resin composites ${ }^{(14)}$. As they are less expensive than resin-based cements and maximize the range of shades available ${ }^{(15)}$.

The hypothesis if this study was that there will be a difference in color change in both type of ceramics and resin cement used.

\section{MATERIALS AND METHODS}

Thirty disk-shaped ceramic specimens were machined out of two types of ceramic blocks, IPS e.max CAD and CERASMART CAD, 15 specimens each. Disks were machined to a uniform thickness of $0.5 \mathrm{~mm} \pm 0.05 \mathrm{~mm}$ from the high translucent blocks of A3 shade using a diamond saw. IPS e.max CAD disks were then crystallized according to the firing parameters listed by the manufacturer as they were tempered at $850{ }^{\circ} \mathrm{C}$ for 25 minutes under a vacuum to reach the fully-crystallized form. For the purpose of standardization one operator performed the polishing of all specimens according to the manufacturer's instructions of each material and the polishing time of each specimen was set for 30 seconds.

A Teflon mold was fabricated with an internal stopper made at $0.6 \mathrm{~mm}$ depth in order to create 0.1 $\mathrm{mm}$ space after placement of the $0.5 \mathrm{~mm}$ ceramic disk to allow for uniform resin cement thickness as well as proper disk placement. Before the application of the resin cement, surface treatment was done to each specimen according to the manufacturer's instructions of each ceramic material. Afterwards, ceramic disks were placed inside the Teflon mold and the resin cement was applied as a thin layer on the treated surface of the ceramic disk and a glass slab was pressed over the cement and ceramic disk using a finger pressure applied on the upper surface of the glass slab. A milar strip was used in between the resin cement and the glass slab for easy removal of the specimens after curing. The excess was removed after curing the resin cement for 2 seconds, then curing was completed for 30 seconds from the polished surface of the ceramic disks.

A laboratory ultraviolet spectrophotometer (Cary 5000 UV-vis-NIR spectrophotometer) was used for the measurement of color coordinates. After each specimen was measured CIELab values where calculated in each time according to the CIELab color system. The specimens were then subjected to accelerated aging test using QUV accelerated weathering tester. Only the polished surface of the disks was exposed to artificial accelerated aging and specimens were stored in the device for 300 hours where the specimens were subjected to 150 cycles of aging each cycle was two hours long. Specimens were measured again by the spectrophotometer device after being artificially aged for 300 hours and the color difference between different groups was calculated according to the following equation:

$$
\Delta \mathrm{E}=\left[\left(\Delta \mathrm{L}^{*}\right)^{2}+\left(\Delta \mathrm{a}^{*}\right)^{2}+\left(\Delta \mathrm{b}^{*}\right)^{2}\right]^{1 / 2}
$$

\section{RESULTS}

Two-way ANOVA was used to study the effect of ceramic type, Cement type and their interaction on color parameters. Bonferroni's post-hoc test was used for pair-wise comparisons when ANOVA test was significant. The significance level was set at $\mathrm{P} \leq 0.05$. Statistical analysis was performed with IBM SPSS Statistics Version 20 for Windows. Descriptive statistics of $\Delta \mathrm{E}$ values are presented in Table (1). 
TABLE (1) Descriptive statistics of color change $(\Delta \mathrm{E})$ mean values

\begin{tabular}{|c|c|c|c|c|c|}
\hline \multirow{2}{*}{$\begin{array}{l}\text { Ceramic } \\
\text { type }\end{array}$} & \multirow{2}{*}{$\begin{array}{l}\text { Cement } \\
\text { type }\end{array}$} & \multirow{2}{*}{$\begin{array}{c}\text { Mean } \\
\Delta \mathrm{E}\end{array}$} & \multirow[b]{2}{*}{$\mathrm{SD}$} & \multicolumn{2}{|c|}{$95 \%$ CI } \\
\hline & & & & $\begin{array}{l}\text { Lower } \\
\text { bound }\end{array}$ & $\begin{array}{l}\text { Upper } \\
\text { bound }\end{array}$ \\
\hline \multirow{3}{*}{ 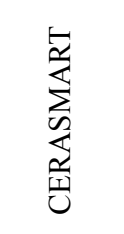 } & $\begin{array}{c}\text { Rely X } \\
\text { Ultimate }\end{array}$ & 5.06 & 0.08 & 4.95 & 5.16 \\
\hline & $\begin{array}{l}\text { Rely X } \\
\text { Veneer }\end{array}$ & 5.32 & 0.16 & 5.12 & 5.53 \\
\hline & Filtek Z350 & 5.60 & 0.11 & 5.46 & 5.74 \\
\hline \multirow{3}{*}{ 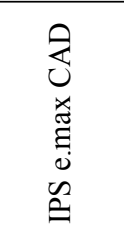 } & $\begin{array}{l}\text { Rely X } \\
\text { Ultimate }\end{array}$ & 4.44 & 0.04 & 4.39 & 4.49 \\
\hline & $\begin{array}{l}\text { Rely X } \\
\text { Veneer }\end{array}$ & 4.74 & 0.05 & 4.67 & 4.8 \\
\hline & Filtek Z350 & 4.97 & 0.07 & 4.88 & 5.07 \\
\hline
\end{tabular}

Statistical analysis of mean $\Delta \mathrm{E}$ values of the ceramic materials revealed that regardless of the cement used, CERASMART showed a statistically significantly higher mean $\Delta \mathrm{E}$ value than e.max (P. $<0.001 *$ ) (Table 2). Meanwhile, Statistical analysis of mean $\Delta \mathrm{E}$ values as a function of resin cement used has shown that, regardless of the ceramic material used, Filtek Z350 showed the statistically significantly highest mean $\Delta \mathrm{E}$ value. A statistically significantly lower mean $\Delta \mathrm{E}$ was found with Rely $\mathrm{X}$ Veneer cement, whereas, Rely X Ultimate cement showed the statistically significantly lowest mean $\Delta \mathrm{E}$ (Table 3).

Two-way ANOVA was done to test statistical significance between variables, where ceramic type and cement type are the independent variable (Table 4).

TABLE (2) The mean, standard deviation (SD) values and results of two-way ANOVA test for comparison between $\Delta \mathrm{E}$ of the two ceramic materials regardless of the cement type.

\begin{tabular}{|c|c|c|c|c|c|}
\hline \multicolumn{2}{|c|}{ CERASMART } & \multicolumn{2}{c|}{ IPS e.max CAD } & \multirow{2}{*}{ P-value } & $\begin{array}{c}\text { Effect size } \\
\text { (Partial eta squared) }\end{array}$ \\
\cline { 1 - 3 } Mean & SD & Mean & SD & & 0.925 \\
\hline
\end{tabular}

*: Significant at $P \leq 0.05$

TABLE (3) The mean, standard deviation (SD) values and results of two-way ANOVA test for comparison between $\Delta \mathrm{E}$ as a function of cement type regardless of ceramic material type.

\begin{tabular}{|c|c|c|c|c|c|c|c|}
\hline \multicolumn{2}{|c|}{ Rely X Ultimate } & \multicolumn{2}{c|}{ Rely X Veneer } & \multicolumn{2}{c|}{ Filtek Z350 } & \multirow{2}{*}{ P-value } & $\begin{array}{c}\text { Effect size } \\
\text { (Partial eta squared) }\end{array}$ \\
\cline { 1 - 4 } Mean & SD & Mean & SD & Mean & SD & & 0.866 \\
\hline $4.75^{\mathrm{C}}$ & 0.33 & $5.03^{\mathrm{B}}$ & 0.33 & $5.29^{\mathrm{A}}$ & 0.34 & $<0.001^{*}$ & 0.866 \\
\hline
\end{tabular}

*: Significant at $P \leq 0.05$, Different superscripts are statistically significantly different 
TABLE (4) The mean, standard deviation (SD) values and results of Two-way ANOVA test for comparison between $\Delta \mathrm{E}$ values between independent variables.

\begin{tabular}{|c|c|c|c|c|c|c|}
\hline \multirow{2}{*}{ Cement type } & \multicolumn{2}{|c|}{ CERASMART } & \multicolumn{2}{|c|}{ IPS e.max CAD } & \multirow{2}{*}{$\begin{array}{c}P \text {-value } \\
\text { (Between ceramic types) }\end{array}$} & \multirow{2}{*}{$\begin{array}{c}\text { Effect size } \\
\text { (Partial eta squared) }\end{array}$} \\
\hline & Mean & SD & Mean & $\mathrm{SD}$ & & \\
\hline Rely X Ultimate & $5.06^{\mathrm{C}}$ & 0.08 & $4.44^{\mathrm{C}}$ & 0.04 & $<0.001^{*}$ & 0.809 \\
\hline Rely X Veneer & $5.32^{\mathrm{B}}$ & 0.16 & $4.74^{\mathrm{B}}$ & 0.05 & $<0.001^{*}$ & 0.793 \\
\hline Filtek Z350 & $5.6^{\mathrm{A}}$ & 0.11 & $4.97^{\mathrm{A}}$ & 0.07 & $<0.001 *$ & 0.813 \\
\hline $\begin{array}{c}P \text {-value } \\
\text { (Between cement types) }\end{array}$ & \multicolumn{2}{|c|}{$<0.001 *$} & \multicolumn{2}{|c|}{$<0.001 *$} & & \\
\hline $\begin{array}{l}\text { Effect size (Partial eta } \\
\text { squared) }\end{array}$ & \multicolumn{2}{|c|}{0.767} & \multicolumn{2}{|c|}{0.762} & & \\
\hline
\end{tabular}

*: Significant at $P \leq 0.05$, Different superscripts in the same column are statistically significantly different. Different letter denote statistical significant difference.

\section{DISCUSSION}

This in-vitro study evaluated the internal color stability of a light-cured, a dual-cured resin cement, and a flowable composite resin. The translucent ceramic material is considered color stable, but it may not be able to mask the discoloration of the underlying resin cement ${ }^{(16)}$. The Teflon mold was made similar to that used by klinic et al ${ }^{(11)}$ in order to obtain a uniform thickness of $0.1 \mathrm{~mm}$ for the resin cements in all the specimens, as different thicknesses of cement might influence the final color of the veneer restoration ${ }^{(17)}$. Thickness of the specimens was $0.5 \mathrm{~mm}( \pm 0.05 \mathrm{~mm})$ in order to reproduce clinical conditions, as the recommended preparation for veneers is $0.5-0.7 \mathrm{~mm}^{(18)}$. Moreover, to allow high light transmission through the ceramic disk to obtain a higher degree of conversion of the underlying resin cements ${ }^{(19)}$. The use of more thickness of ceramic specimen decreased the $\Delta \mathrm{E}$ values when compared with the $0.5 \mathrm{~mm}$ thickness. It was shown in a previous study that $0.5 \mathrm{~mm}$ thick porcelain disk would not mask the difference in hue amongst different luting materials ${ }^{(20)}$.
A spectrophotometer was preferred instead of visual examination for precise, reproducible and statistically utilizable results ${ }^{(21)}$. The advantages of spectrophotometric analysis with the CIE L*a*b* system is the detection of color changes that are not visible to the human eye and the ability to express color differences in units that may be related to visual perception and clinical significance ${ }^{(22)}$.

Accelerated aging was carried out in the present study using a weathering process. The use of this method in-vitro studies is convenient and can provide more realistic expectations of the long-term outcome of restorations ${ }^{(23)}$. The manufacturer of the artificial aging chamber claims that 300 hours in the weathering chamber is equivalent to one year of clinical service ${ }^{(16)}$. However, there are no data to support this claim.

The hypothesis of this study was accepted as there is statistically significant deference between the mean $\Delta \mathrm{E}$ of IPS e.max $\mathrm{CAD}(\Delta \mathrm{E}=4.72)$ which is lower than the mean $\triangle \mathrm{E}$ of CERASMART (5.33). There was also a significant difference between the cements used as Filtek Z350 flowable composite showed the highest mean $\Delta \mathrm{E}$ (5.29), while Rely X 
Ultimate showed the lowest mean $\Delta \mathrm{E}$ (4.75). The color change that occurred for all types of cements was beyond the clinically acceptable range $(\Delta \mathrm{E} \geq$ 3.3). The reason for these results may be the small thickness of the ceramic disks used and their high translucency properties that prevent them from masking the high color change that occurred in the resin cement.

According to the effect of ceramic type, the results of the present study are in agreement with Gawriołek et al ${ }^{(6)}$ who concluded that ceramic materials exhibit better color stability than composite resins. The more change in color that occurred in CERASMART may be due to the resin content of this ceramic block and the presence of polymer. As to the effect of cement type, the color change among the three cements may be attributed to difference in composition of the three resin cements and the affinity of their resin matrix to absorb water as the resin matrix of Rely X veneer and Filtek Z350 flowable composite is composed of Bis-GMA which is considered to be more prone to color change due to of its high water absorption and solubility characteristics ${ }^{(24)}$.

\section{CONCLUSIONS}

Within the limitations of the current study, it was concluded that, the color changes of resin cement materials in all groups were above the clinically acceptable value $(\Delta \mathrm{E} \geq 3.3)$. RelyX Ultimate showed higher color stability than the other tested materials. Resin cements affect the final color of thin restorations. IPS e.max CAD showed better color stability than CERASMART CAD.

\section{REFERENCES}

1. Peumans M, Van Meerbeek B, Lambrechts P, Vanherle G. Porcelain veneers: a review of the literature. J Dent. 2000; 28:163-77.

2. Pires LA, Novais PM, Araújo VD, Pegoraro LF. Effects of the type and thickness of ceramic, substrate, and cement on the optical color of a lithium disilicate ceramic. J Prosthet Dent. 2017; 117:144-49.
3. Morimoto S, Albanesi RB, Sesma N, Agra CM, Braga MM. Main clinical outcomes of feldspathic porcelain and glass-ceramic laminate veneers: a systematic review and meta-analysis of survival and complication rates. Int $\mathbf{J}$ Prosthodont. 2016; 29:38-49.

4. Calgaro PA, Furuse AY, Correr GM, Ornaghi BP, Gonzaga CC. Post cementation colorimetric evaluation of the interaction between the thickness of ceramic veneers and the shade of resin cement. Am J Dent. 2014; 27:191-4.

5. Turgut S, Bagis B, Ayaz EA. Achieving the desired color in discolored teeth, using leucite-based CAD-CAM laminate systems. J Dent. 2014; 42:68-74.

6. Gawriołek M, Sikorska E, Ferreira L, Costa A, Khmelinskii I, Krawczyk A, Sikorski M, Koczorowski R. Color and luminescence stability of selected dental materials in vitro. J Prosthodont. 2012; 21:112-22.

7. Topcu F, Sahinkesen G, Yamanel K. Influence of different drinks on the colour stability of dental resin composites. Eur J Dent. 2009; 3:50-6.

8. Awada A, Nathanson D. Mechanical properties of resinceramic CAD/CAM restorative materials. $J$ Prosthet Dent. 2015; 114(4):587-93.

9. Lee YK, Lu H, Powers JM. Changes in opalescence and fluorescence properties of resin composites after accelerated aging. Dent Mater. 2006; 22:653-60.

10. Hobo S. Porcelain laminate veneers with three-dimensional shade reproduction. Int Dent J. 1992; 42:189-98.

11. Kilinc E, Antonson SA, Hardigan PC, Kesercioglu A. Resin cement color stability and its influence on the final shade of all-ceramics. J Dent. 2011; 39: 30-6.

12. Santos Jr, El Mowafy O, Rubo JH, Santos MJ. Hardening of dual-cure resin cements and a resin composite restorative cured with QTH and LED curing units. J Canad Dent Assoc. 2004; 70:323-8.

13. Kumbuloglu O, Lassila LV, User A, Vallittu PK. A study of the physical and chemical properties of four resin composite luting cements. Int J Prosthodont. 2004; 17:357-63.

14. Archegas LR, de Menezes Caldas DB, Rached RN, Soares P, Souza EM. Effect of ceramic veneer opacity and exposure time on the polymerization efficiency of resin cements. Oper Dent. 2012; 37:281-9.

15. Almeida JR, Schmitt GU, Kaizer MR, Boscato N, Moraes RR. Resin-based luting agents and color stability of bonded ceramic veneers. J Prosthet Dent. 2015; 114:272-7. 
16. Al Ghazali N, Laukner J, Burnside G, Jarad FD, Smith $\mathrm{PW}$, Preston AJ. An investigation into the effect of try-in pastes, uncured and cured resin cements on the overall color of ceramic veneer restorations: an in vitro study. $\mathrm{J}$ Dent 2010; 38(2):78-86.

17. Kious AR, Roberts HW, Brackett WW. Film thicknesses of recently introduced luting cements. J Prosth Dent. 2009; 101:189-92.

18. Turgut S, Bagis B. Color stability of laminate veneers: An in vitro study. J Dent. 2011; 39:57-64.

19. Arrais CA, Rueggeberg FA, Waller JL, de Goes MF, Giannini M. Effect of curing mode on the polymerization characteristics of dual-cured resin cement systems. J Dent. 2008; 36:418-26.

20. Hekimoğlu C, Anil N, Etikan I. Effect of accelerated aging on the color stability of cemented laminate veneers. Int $\mathbf{J}$ Prosthodont. 2000; 13:29-33.

21. Kolbeck C, Rosentritt M, Lang R, Handel G. Dicoloration of facing and restorative composites by UV-irradiation and staining food. Dent Mater J. 2006; 22:63-8.

22. O'Brien WJ, Hemmendinger H, Boenke KM, Linger JB, Groh CL. Color distribution of three regions of extracted human teeth. Dent Mater. 1997; 13:179-85.

23. Nikzad S, Azari A, Poursina M. Effects of beverage colorants and accelerated aging on the color stability of indirect resin composites. J Dent Sci.2012; 7:231-7.

24. Stawarczyk B. Discoloration of manually fabricated resins and industrially fabricated CAD / CAM blocks versus glass ceramic: Effect of storage media, duration, and subsequent polishing. Dent mater J. 2012; 31:377-83. 